\title{
On tridimensional rip current modeling
}

Patrick Marchesiello ${ }^{\mathrm{a}, *}$, Rachid Benshila ${ }^{\mathrm{b}}$, Rafael Almar ${ }^{\mathrm{a}}$, Yusuke Uchiyama ${ }^{\mathrm{c}}$, James C. McWilliams $^{\mathrm{d}}$, Alexander Shchepetkin ${ }^{\mathrm{d}}$

\author{
${ }^{a}$ IRD/LEGOS, Toulouse, France \\ ${ }^{b}$ CNRS/LEGOS, Toulouse, France \\ ${ }^{c}$ Kobe University, Kobe, Japan \\ ${ }^{d}$ UCLA, Los Angeles, California
}

\begin{abstract}
Do lateral shear instabilities of nearshore circulation account for a substantial part of Very Low-Frequency (VLF) variability? If yes, it would promote stirring and mixing of coastal waters and surf-shelf exchanges. Another question is whether tridimensional transient processes are important for instability generation. An innovative modeling system with tridimensional wave-current interactions was designed to investigate transient nearshore currents and interactions between nearshore and innershelf circulations. We present here some validation of rip current modeling for the Aquitanian coast of France, using in-situ and remote video sensing. We then proceed to show the benefits of 3D versus 2D (depth-mean flow) modeling of rip currents and their low-frequency variability. It appears that a large part of VLF motions is due to intrinsic variability of the tridimensional flow. 3D models may thus provide a valuable, only marginally more expensive alternative to conventional 2D approaches that miss the vertical flow structure and its nonlinear interaction with the depth-averaged flow.
\end{abstract} Keywords: Rip current, Intrinsic variability, Tridimensional modeling, Video imaging, Biscarrosse beach.

\section{Introduction}

Rip currents are narrow, seaward currents that extend from the inner surf zone out through the line of breaking waves. Rip currents are usually long (100 m), narrow (10 m)

${ }^{*}$ Corresponding author

Email address: Patrick.Marchesiello@ird.fr (Patrick Marchesiello) 

7 review).

and intense jet flows (reaching 1-2 m/s). They appear to span the entire water column in the shallow breaking zone but remain confined near the surface as they flow past the breaking zone into deeper water, forming strong vertical shear (Haas and Svendsen, 2002). Understanding the complex tridimensional dynamics of rip currents remain a relevant scientific challenge as these currents play a key role on material dispersion and morphodynamics across the surfzone and are a major hazard to swimmers (see MacMahan et al., 2006, for a

Despite substantial evidence of tridimensional flow structure, most modeling studies of rip currents are performed using depth-integrated shallow water equations. Bruneau et al. (2011) used this class of model (MARS coupled with SWAN) to study the Aquitanian coast of France. In June 2007 an intense 5-day field experiment was conducted at the mesotidal/macrotidal wave-dominated Biscarrosse Beach on a well-developed bar and rip morphology. Previous analysis of the field data exposed the main characteristics of a tidemodulated rip current driven by low- to high-energy shore-normal waves (Bruneau et al., 2009b). The model was able to reproduce some of the rip current characteristics but discrepancies with observations were evidenced at the rip neck, this narrow jet-like region where the rip current velocity is maximum.

In a parallel study, Bruneau et al. (2009a) showed occurrence of rip current variability, referred to as Very Low Frequency motions (VLF), in the rip neck where VLF pulsations were most intense (reaching $1 \mathrm{~m} / \mathrm{s}$ on time scales of 10 to $30 \mathrm{~min}$ ). These oscillations were consistent with shear instabilities similar to those produced by the analytical solution of Haller and Dalrymple (2001). Intrinsic variability of the nearshore circulation is an alternative to vorticity generation by short-crested wave breaking (Peregrine, 1998; Spydell and Feddersen, 2009) or low-frequency wave forcing (Long and Özkan-Haller, 2009), but the contribution of each component is highly debated.

In this paper, we extend on the work of Bruneau et al. (2009a, 2011) to show that tridimensional dynamics must be accounted for in the study of rip currents, i.e., in their persistent structure and instability behavior. Our results are relevant to the ongoing discussion on intrinsic and extrinsic origins of VLF energy. Before addressing these points, 
1 we present our model setup and calibration technique, relying on breaking wave dissipation 2 patterns provided by video monitoring.

\section{Methods}

\subsection{Video monitoring}

A main limitation for understanding nearshore processes is lack of appropriate observation. Traditional in situ measurement techniques can provide high sampling rates and a direct estimation of many parameters, but with coarse spatial resolution that often misses complex dynamical interactions. Additionally, instruments must be deployed in high-energy and sometimes hazardous environments (wave-breaking, strong currents), endangering not only the instruments, but also the personnel involved. As an alternative, remote sensing techniques can provide synoptic coverage over large areas with a wide range of temporal and spatial resolutions.

The video imaging technique (Holman and Haller, 2013) is particularly suited to coastal observation thanks to low-cost and easy deployment and maintenance of the camera-based technology. It is also considered as a non-disruptive observation technique for nearshore research. A video system was deployed at Biscarrosse beach in 2007 (Almar et al., 2009; Fig. 1) and inversion methods were revisited to provide estimation of the complete nearshore system, i.e., hydrodynamics (wave characteristics, water level, currents and breaking wave dissipation rates) and morphodynamics (shoreline, sub- and inter-tidal bathymetry) continuously and over long-term periods and large areas (approximate $2 \times 1 \mathrm{~km}$ ). Here we only use information on wave breaking dissipation.

Time-exposure images were generated by averaging over 1200 consecutive images (10 min) four times per hour during daylight. The 5-camera images were rectified from pixel to world coordinates (Holland et al., 1997) and merged to yield a single plan view image referenced to the tidal level. The grid resolution in the plan view images is $2 \mathrm{~m}$ (over the inner-bar area facing the video cameras, the pixel footprint is about 0.5 and $1 \mathrm{~m}$ in alongshore and cross-shore directions, respectively; it increases to about 10 and $20 \mathrm{~m}$ at both alongshore 
ends of the field site). When time-exposure images are of good quality (e.g., no sunglint), wave-breaking over the underlying sand bar morphology is revealed by a smooth band of white. After removing the background pixel intensity value, the normalized light intensity field can be used as a proxy of wave energy dissipation rate (Lippmann and Holman, 1989; Haller and Catalán, 2009; Almar et al., 2010).

\subsection{The model}

The objective of the paper is to assess the benefit of tridimensional coastal models. An innovative modeling approach for 3D wave-current interactions (McWilliams et al., 2004) was implemented in the Regional Oceanic Modeling System (ROMS; Shchepetkin and McWilliams, 2005) by Uchiyama et al. (2010) and used for an idealized study of longshore current shear instability (Uchiyama et al., 2009). An upgraded implementation is proposed here for the AGRIF version of ROMS (Penven et al., 2006; Debreu et al., 2012). It allows additional capabilities such as nesting and wetting/drying (Warner et al., 2013), the latter being crucial to the meso- macro-tidal environment of Biscarrosse beach.

ROMS is a hydrostatic, incompressible, free-surface and terrain-following coordinate model with non-conservative forcing, diffusion, and bottom drag. It uses baroclinic/barotropic mode splitting, with explicit fast time-stepping and subsequent conservative averaging of barotropic variables. The discretization is with high-order finite differences that provide both accurate and cost-effective solutions.

The interaction of surface gravity waves and currents is implemented in ROMS through vortex-force (VF) formalism. Eulerian wave-averaged current equations for mass, momentum, and tracers are included based on an asymptotic theory by McWilliams et al. (2004) plus non-conservative wave effects.

The advantage of the vortex-force over radiation-stress formalism is to cleanly separate conservative and non-conservative effects on currents; it also unfolds the vortex force and Bernoulli head components of conservative effects. Material advection by Stokes drift is another important conservative effect. The non-conservative components (acceleration / dissipation) are those that require parametrization and are thus responsible for the largest 

4 2011).

Non-conservative wave effects are due to wave breaking, associated surface roller waves, bottom streaming, and wave-enhanced vertical mixing and bottom drag. The nonlinear parameterization of Soulsby (1995) for wave-enhanced bottom drag is particularly relevant to the present case with strong tidal flow:

$$
\vec{\tau}_{b}=\vec{\tau}_{c}\left[1.0+1.2\left(\frac{\left|\vec{\tau}_{w}\right|}{\left|\vec{\tau}_{w}\right|+\left|\vec{\tau}_{c}\right|}\right)^{3.2}\right]
$$

with

$$
\vec{\tau}_{c}=\rho_{0} \frac{\kappa^{2}}{\left[\ln \left(\frac{z_{r}}{z_{0}}\right)\right]^{2}}|\vec{u}| \vec{u}=\rho_{0} C_{D}|\vec{u}| \vec{u}
$$

and

$$
\left|\vec{\tau}_{w}\right|=\frac{1}{2} \rho_{0} f_{w}\left|\vec{u}_{w}\right|^{2}
$$

${ }_{5} \quad \vec{\tau}_{c}$ and $\vec{\tau}_{w}$ are bottom stresses due to currents and waves; $\kappa$ is Von Karman constant; $z_{r}$ is the 6 bottom-most grid cell height (for horizontal velocities); $z_{0}$ is bottom roughness (taken here 7 as $1 \mathrm{~cm}) ; f_{w}$ is a wave friction factor dependent on bottom wave orbital velocity $\left|\vec{u}_{w}\right|$ and 8 wave frequency (see Blaas et al. (2007), for details on ROMS implementation). All other 9 parameterizations are described in Uchiyama et al. (2010).

The currents are coupled with a ray-theory spectrum-peak wave propagation model (WKB model) describing wave crest conservation with wave refraction and conservation of both wave and roller action (wave rollers cause a lag in the transfer of momentum to the currents in the wave breaking process). The wave model includes the Doppler-shifted current effect on waves and dissipation due to shoaling-induced wave breaking and bottom drag. A description is given in Uchiyama et al. (2010) and Weir et al. (2011), who used it for an idealized study of rip currents using the vortex-force formalism. The system is thus fully coupled within a unique executable code that is both convenient and computationally efficient. 
Biscarrosse Beach is located along the Aquitanian coast of southwest France, exposed to the powerful North Atlantic swell. The wave climate is characterized by a mean offshore significant wave height of $1.4 \mathrm{~m}$, mean period of $6.5 \mathrm{~s}$ and mean West-North-West direction (Butel et al., 2002). The tide is semi-diurnal, with neap and spring tidal ranges of 2 and $5 \mathrm{~m}$, respectively (i.e., meso-macro tidal range). Biscarrosse Beach is mostly intermediate double-barred following the classification of Wright and Short (1984). The inner bar in the intertidal zone exhibits a transverse bar and rip morphology with mean rip spacing of about 400 m (Castelle et al., 2007).

The coupled model is applied to the nearshore zone of Biscarrosse Beach during the 2007 field measurement campaign (see bathymetry in Fig. 2). From an ADCP deployed in $10 \mathrm{~m}$ water depth (at low tide), offshore measurements of tidal elevation, wave height and winds ${ }^{1}$ are used to force the model for 5 days from the 13 th to the 17 th of June 2007. The tidal range varied from 3.3 to $3.8 \mathrm{~m}$, the offshore significant wave height from 0.5 to $3 \mathrm{~m}$ (mostly swell), peak wave period from 8 to $11 \mathrm{~s}$, and wave angle often close to shore normal (Bruneau et al., 2009b, 2011). Open boundary conditions must handle outgoing perturbations generated inside the computational domain while external forcing is specified. To that end, we use a combination of characteristic methods for barotropic tides and radiation equations for baroclinic currents, with the addition of Newtonian and viscous damping (Marchesiello et al., 2001). Offshore waves are simply specified, as coastal reflection was negligible.

The horizontal resolution is $5 \mathrm{~m}$ for the standard simulation but sensitivity tests are usually done at a lower resolution of $10 \mathrm{~m}$. In addition, a simulation at 20-m resolution allows us to test the convergence of numerical solution. On the vertical, there are 20 terrainfollowing (sigma) levels equally spaced and the water has a constant density $\rho_{0}$ (there is no surface or lateral buoyancy forcing). The horizontal eddy viscosity is given by the flow- and

\footnotetext{
${ }^{1}$ The wind effect on nearshore circulation is weak overall during the experiment and will not be discussed further here.
} 
resolution-dependent Smagorinsky (1963) formulation:

$$
\nu_{T}=\left(C_{S} \Delta\right)^{2}|S|
$$

1 where $S$ is the strain rate, $\Delta$ the model horizontal resolution and $C_{S}$ the Smagorinsky coef-

2 ficient. With a standard value of $C_{S}=0.1, \nu_{T}$ is always lower than $1 \mathrm{~m}^{2} / \mathrm{s}$ in our simulations 3 (this point is discussed in Section 5). The baroclinic time step is 2 seconds and 30 barotropic 4 sub-steps are performed every baroclinic step. The cost of $3 \mathrm{D}$ computations is thus moderate 5 and the full 3D model is only marginally more expensive than the $2 \mathrm{D}$ part $^{2}$.

\section{3. Calibration and Validation}

\footnotetext{
${ }^{2}$ We use 144 CPUs (on an IBM Power computer at the French IDRIS center) to integrate the 5-m resolution model on $187 \times 205 \times 20$ grid points. The elapsed time for the 5 day simulation is about 7 hours. It is 6 hours with the equivalent 2D model (only the depth-averaged part of the equations is integrated in this case). We thus estimate the cost of the 3D model as only $15 \%$ higher than the $2 \mathrm{D}$ model.
} 
more intense breaking than other available choices (Weir et al., 2011):

$$
\epsilon_{b}=\frac{3 \sqrt{\pi}}{16} \rho_{0} g f_{p} B_{b}^{3} \frac{H_{r m s}^{3}}{D}\left[1+\tanh \left\{8\left(\frac{H_{r m s}}{\gamma_{b} D}-1\right)\right\}\right]
$$

$$
\left[1-\left\{1+\left(\frac{H_{r m s}^{2}}{\gamma_{b} D}\right)^{-\frac{5}{2}}\right\}\right]
$$

$1 \quad f_{p}$ is the peak frequency of the waves, $H_{r m s}$ is the root-mean-square wave height (twice 2 the amplitude), and D the bottom depth. This parametrization relies on two empirical 3 constants: the breaking wave parameter $\gamma_{b}$ is the wave height-to-depth ratio for which all 4 waves are assumed to be breaking and $B_{b}$ is the fraction of foam on the face, accounting for 5 the type of breaker.

10-min average video recording provides a high-resolution and statistically reliable image 7 of the wave breaking pattern. Fig. 3 (top panels) shows two examples for low- and high8 energy conditions on June 14 and 16 respectively. Under the assumption that light intensity 9 varies as the dissipation of the incident wave, the video patterns can be compared (after 10 normalization by rescaling between 0 and 1 ) with the model patterns of wave dissipation 11 (Fig. 3, bottom panels). We tested various combinations of the two breaking parameters ${ }_{12} \gamma_{b}$ and $B_{b}$ and visually estimated a best fit to cross-shore patterns - looking especially 13 at surfzone width and position - given by the clearest video images. This method is

suboptimal compared with data assimilation techniques (currently under development) but proved successful. Values of 0.3 and 1.3 , for $\gamma_{b}$ and $B_{b}$ respectively, provide the best fit from our experience. There is no need here to add a time dependence on $\gamma_{b}$ as the fit to data appears valid for both low- and high-energy conditions (Fig. 3), justifying the use of Eq. 5 from Church and Thornton, 1993. The fraction $\alpha_{r}$ of breaking waves converted into rollers is taken as 0.5 and reveals only little sensitivity.

\subsection{Validation with in-situ data}

Figure 4 presents a model-data comparison for wave height and cross-shore currents at station S4 located on the edge of the rip neck (see Fig. 2; the S4 Interocean electromagnetic current meter acquired velocity data about $40 \mathrm{~cm}$ above ground at a $2-\mathrm{Hz}$ sample rate). 
1 The observation shows a strong increase of wave height on the 15th of June due to offshore 2 forcing but strongly modulated by large tides (with range of close to $4 \mathrm{~m}$ ) that shift back 3 and forth the cross-shore position of the breaking line. High-energy conditions from June 4 15th lead to strong offshore-directed rip currents in excess of $75 \mathrm{~cm} / \mathrm{s}$.

The model is able to reproduce the wave height evolution (Fig. 4, upper panel; Corr=0.95; - $\mathrm{RMSE}=13 \mathrm{~cm}$ ). The fit is quite remarkable during high-energy conditions. The directional wave spectra presented in Bruneau et al. (2009b) is composed of narrow-banded swell during both low- and high-energy conditions (in the latter case, superimposed on a large directional spread of weaker wind waves). Therefore, the assumption is validated that nearshore waves in this experiment are well described by ray equations driving a single wave with root-meansquare wave height and frequency corresponding to the spectral peak.

There is an equally remarkable fit of simulated currents with data (Fig. 4, lower panel; Corr $=0.83 ; \mathrm{RMSE}=14 \mathrm{~cm} / \mathrm{s})$. A series of rip events are present in both model and observations and are correlated with tides. Here, rip events appear as burst of momentum during flood and ebb phases (maximum currents are reached between low- and mid-tide of each phase) separated by periods of inactivity at high tides. Therefore, rip currents have a dual cycle of tidal and semi-tidal periods. During events, shifting negative and positive velocities are observed at $\mathrm{S} 4$ because it is on the northern edge of the rip channel in a transitional position between shoreward and seaward flow (setting up a mooring in the channel is a real challenge). If rip events appear as tidally-driven slow variations of cross-shore currents, faster oscillations are present as well, most prominent during rip events; they will be treated in Section 5.

Because of strong horizontal and vertical shear at S4, the model-data comparison is sensitive to both vertical and horizontal interpolation of the model solution to the measurement point. The sensor's vertical displacement must be accounted for (its position varies in time between $30-40 \mathrm{~cm}$ above the sea floor). This being considered, the match is excellent in terms of correlation and standard deviation, in contrast with known 2D simulations (Bruneau et al., 2011, their Figure 7). 


\section{Rip current sensitivity to the vertical dimension}

\section{4.1. Comparison with a two-dimensional simulation}

To analyze the extent of errors related to the shallow water hypothesis, we now compare our standard solution with a two-dimensional version of ROMS. In this case the barotropic mode is advanced alone. Note that the cross-shore barotropic flow (depth-averaged $\bar{u}$ ) of the $2 \mathrm{D}$ model is different from that of the $3 \mathrm{D}$ model because the latter receives contribution from the baroclinic flow $u^{\prime}$ :

$$
\begin{aligned}
\frac{\partial \bar{u}}{\partial t}=-\left[\frac{\partial \bar{u} \bar{u}}{\partial x}+\frac{\partial \bar{u} \bar{v}}{\partial y}\right]+\overline{V F}+f \bar{v}-g \frac{\partial \eta}{\partial x}+F_{u}+D_{u}-\frac{\tau_{b}}{\rho_{0} H} & -\left[\frac{\partial \overline{u^{\prime} u^{\prime}}}{\partial x}+\frac{\partial \overline{u^{\prime} v^{\prime}}}{\partial y}\right]-\frac{1}{\rho_{0}} \frac{\partial \bar{P}}{\partial x}
\end{aligned}
$$

3 The first line of Eq. 6 contains the terms of a wave-averaged shallow water model: time 4 rate, advection, vortex force, Coriolis force, pressure gradient (inclusive of wave effects on 5 surface pressure, e.g. setup/setdown), external forcing (wind stress, wave-breaking and 6 bottom streaming), lateral dissipation and bottom friction. The second line contains the 7 coupling terms between barotropic and baroclinic modes, i.e., the baroclinic contribution 8 to nonlinear advection (divergence of baroclinic Reynolds stresses of type $\overline{u^{\prime} u^{\prime}}=\overline{u u}-\bar{u} \bar{u}$ ) 9 and the depth-averaged internal pressure gradient. We neglect the latter here as we assume 10 no stratification but it may be of importance out of the surf zone (Hally-Rosendahl et al., 11 2014).

For the bottom drag due to currents $^{3}$, we can derive an equivalent formulation to the 3D case, assuming that in shallow water the logarithmic layer extends all the way to the surface. In this case, integrating the velocity profile provides a $2 \mathrm{D}$ drag coefficient of the form:

$$
C_{D}=\left(\frac{u^{*}}{|\vec{u}|}\right)^{2}=\left(\frac{u^{*}}{\frac{1}{H} \int_{0}^{H} \frac{u^{*}}{\kappa} \ln \frac{z}{z_{0}} d z}\right)^{2}=\frac{\kappa^{2}}{\left[\ln \frac{H}{z_{0}}-1\right]^{2}}
$$

\footnotetext{
${ }^{3}$ The bottom stress due to waves has no dependence on the vertical grid and is the same in $2 \mathrm{D}$ and $3 \mathrm{D}$ models
} 
where $H$ is total depth and $u^{*}$ the friction velocity. Eq. 7 would ensure that the $2 \mathrm{D}$ bottom stress equals that of the 3D model for the same barotropic flow. This, however, turns out to be wrong: the 2D drag coefficient in Eq. 7 is too weak for 2D and 3D bottom drags to match. A closer match (also between the 2D model circulation and observations) is obtained with a constant linear coefficient of $0.0025 \mathrm{~m} / \mathrm{s}$ in the $2 \mathrm{D}$ model. This is a first indication that the nearshore circulation off Biscarrosse Beach is poorly approximated by a $2 \mathrm{D}$ flow with logarithmic layer, as confirmed below.

Figure 5 shows a comparison of the barotropic components of ROMS in its shallow water and 3D versions. It appears that the shallow water model yields weaker correlations with data and clearly underestimates the cross-shore flow, especially during high-energy conditions (RMSE between observations and model estimates is then larger by a factor of 2.5). Over the whole time series, the standard deviation of $\bar{u}$ at $\mathrm{S} 4$ is about $10 \mathrm{~cm} / \mathrm{s}$ in the $2 \mathrm{D}$ model compared with $22 \mathrm{~cm} / \mathrm{s}$ for $u$ in the 3D model and $26 \mathrm{~cm} / \mathrm{s}$ in the observations. Interestingly, the barotropic mode of the 3D model shows larger velocities $(14 \mathrm{~cm} / \mathrm{s}$ standard deviation), especially during high-energy conditions, implying a significant role played by the baroclinic contribution to barotropic nonlinear terms.

\subsection{Analysis of $2 D / 3 D$ coupling}

To analyze the 2D/3D coupling effect, we choose a low-energy rip event (June 14 around 9 a.m.) that is isolated from surrounding flow systems (in contrast, high-energy conditions show frequent interactions). Figure 6 presents instantaneous maps of baroclinic Reynolds stress $\overline{u^{\prime} u^{\prime}}$ and associated divergence term $-\partial \overline{u^{\prime} u^{\prime}} / \partial x$ (the other term is weaker). The Reynolds stress field is a measure of vertical shear variance showing that departure from depth-averaged flow is significant everywhere in the surf zone and along the rip current. The Reynolds stress divergence is the baroclinic part of advection that exchange momentum between the baroclinic and barotropic circulation. In Figure 6, the rip neck stands as a location of positive advection, i.e., the surface current and vertical shear are accelerated along the seaward rip current at the expense of the depth-averaged flow (increase of $\bar{u}$ but weakening of $|\bar{u}|$ since $\bar{u}<0)$. 
Figure 7 compares baroclinic advection to the other terms of the depth-averaged crossshore momentum budget (Eq. 6). As a whole, rip current system dynamics (right panel of Fig. 7) result from a balance between breaker acceleration, advection and pressure gradients (vortex force, bottom drag and streaming are not negligible but lesser players). Wave breaking accelerates the seaward flow over sand bars and builds a strong pressure gradient that pushes the rip current in the feeder zone.

The rip current is then advected from the feeder zone $(250-300 \mathrm{~m})$ to the rip neck (300$350 \mathrm{~m}$ ) as confirmed by looking more specifically at the momentum budget along the rip channel (bottom panel of Fig. 7): barotropic advection goes from positive (rip deceleration) to negative values (acceleration). In the feeder zone, the current is barotropic as illustrated by a section of cross-shore currents (Fig. 8; left panel) but as water deepens further offshore, baroclinic advection becomes a major player. Its strong positive values in the rip neck indicate a conversion from barotropic to baroclinic currents. About half of the barotropic flow advected to the neck area is converted into baroclinic flow. This is associated with a strong increase of vertical shear (Fig. 8), reminiscent of laboratory measurements by Haas and Svendsen (2002; e.g., their Fig. 12). As a result, the surface flow keeps its speed along the channel while the barotropic flow is largely reduced, a process called surface confinement or trapping (Shepard et al., 1941). During this process, bottom currents and drag are considerably reduced and even reversed (Fig. 7 and 8).

Interestingly, the barotropic current is also decelerated in the neck area by a positive pressure gradient. The latter results from wave shoaling enhanced by the surface rip current, which has thus a negative feedback effect on depth-averaged rip currents (Yu and Slinn, 2003; Weir et al., 2011).

Large Reynolds stress values are also evidenced over sand bars in the onshore flow region of the rip system (Fig. 6). They are related to the circulation formed by a strong surface onshore flow and opposing seaward acceleration by pressure gradients (Fig. 8; right panel). Baroclinic advection seems to act in this case as a redistribution process that increases barotropic flow in the inner surf and feeder zones, at the expense of the outer surf zone. The increased barotropic flow is then advected to the rip neck by the depth-averaged recircula- 

7 1987).

tion. Therefore, the larger rip neck transport in the 3D versus 2D simulation (Figure 5) is not locally generated but provided by the strong recirculation system, which redistributes surface-trapped currents into the rip feeder zone.

These results are relevant to modeling strategies, as they imply that nearshore circulation cannot simply be addressed by linear combination of a depth-averaged model and a vertical profile technique, a common approach in morphological models (e.g., De Vriend and Stive,

\subsection{Sensitivity of the 3D solution}

The vertical structure of the 3D flow has several dependencies. In particular, it is affected by the profile distribution function of breaking and roller acceleration. As for Uchiyama et al. (2010), the best fit to data is obtained with a surface-intensified breaking force (varying as $\cosh \left[(z+D) /\left(a_{b} H_{r m s}\right)\right]$, where $a_{b}$ is a constant set to 0.2$)$, that allows an undertow to develop over the bar crests.

The model results are also sensitive to the bottom roughness length $z_{0}$ used in the parametrization of bottom stress due to currents (Eq. 2). Its impact on the magnitude of cross-shore currents is shown in Figure 9. A relatively large roughness value of $1 \mathrm{~cm}$ (our reference value) provides a good match with data, while lower values tend to produce excessive flow speed. Roughness lengths of $1 \mathrm{~mm}$ and $0.1 \mathrm{~mm}$ produce standard deviations of 32 and $36 \mathrm{~cm} / \mathrm{s}$ respectively, i.e., higher than the $26 \mathrm{~cm} / \mathrm{s}$ value observed. In contrast, the current's magnitude is weakly affected by lateral viscosity (not shown) unless very high values of the Smagorinsky coefficient $\left(C_{S}=1\right)$ are used. These conclusions hold for the steady part of rip currents (i.e., slowly varying with tide and wave forcing) and higher frequencies are explored in the following.

\section{Rip current instabilities}

Very Low Frequency (VLF) motions are described as ubiquitous slow oscillations of the nearshore circulation at periods longer than 5 min (and with uncertain upper limits), i.e., slower than infragravity waves referred to as low-frequency motions (MacMahan et al., 
1 2004). Shear instability of longshore currents are generally admitted as an important process 2 for VLF generations, but for rip currents an important part of the literature associates 3 VLF motions with modulation of the wave forcing (Long and Özkan-Haller, 2009; Spydell 4 and Feddersen, 2009). Yet, Kennedy (2003) suggests that wave group-forced rip current 5 pulsations may be more active on timescales of several minutes than 10 s of minutes. Intrinsic 6 instabilities of rip currents are thus potentially important for slow pulsations. Our single7 wave forcing approach (wave forcing varies at time-scales longer than 2 hours in the model) 8 is suited to explore that part of VLF motions and quantify it by comparison with data.

\section{5.1. Background}

Haller and Dalrymple (2001) developed an analytic depth-averaged model to study the

\footnotetext{
${ }^{4}$ Exponential growth of normal modes along the jet axis is considered with real frequency and complex wave number

${ }^{5}$ The Bickley jet is a parallel flow with profile function $\operatorname{sech}^{2}=1 / \cosh 2$ about the centerline and has inflection points (change of sign of vorticity gradients) satisfying the Rayleigh criterion for shear-flow instability. It produces two types of unstable modes: sinuous and varicose
} 
1 (and wavelength of about $200 \mathrm{~m}$ ), with faster oscillations for stronger rips. In Haller and 2 Dalrymple (2001), viscosity, bottom friction and bottom slope play a large role in controlling 3 vorticity (through offshore jet spreading) and thus the instability process. In general, friction 4 has a strong stabilizing effect and would increase the period of unstable oscillations. The 5 bottom slope has a similar effect. Although vortex stretching tends to reduce jet spreading 6 (as opposed to bottom friction), continuity of the depth-averaged flow has a stronger effect 7 in reducing jet speed. In the tridimensional problem, surface trapping past the surf zone 8 would be less sensitive to both vortex stretching and continuity effects but with uncertain 9 outcome on the overall contribution of bottom slope to jet vorticity.

If the angle of incidence of the waves is nearly shore-normal (below about $3^{\circ}$ ), a negative feedback of rip currents on wave forcing is known to reduce their cross-shore extension and concentrate their energy nearshore (Yu and Slinn, 2003; Özkan-Haller and Li, 2003; Weir et al., 2011). Kennedy and Zhang (2008) developed a stability analysis including such wave-current interactions. The rip feedback on wave forcing is shown to reduce the offshore extension of both sinuous and varicose modes. Some of these sinuous modes may explain the fluctuating circulation cell described by MacMahan et al. (2004). In addition, Kennedy and Zhang (2008) expose a slower pulsation due to a wave-current-type instability that develops for small wave heights (also seen in the numerical experiments of Haas et al., 2003). Wave-current modes are a transient (non-equilibrated) expression of the negative feedback mechanism between rip current and wave breaking ${ }^{6}$. These modes have periods longer than shear instabilities (beyond $30 \mathrm{~min}$ ) and may develop downstream of the jet, much as a convective instability. However, their role in realistic configurations is uncertain.

\footnotetext{
${ }^{6}$ Due to the current effect on waves, the rip current slows down waves in the rip channel and causes cross-shore pressure gradients and breaking that weakens the rip. This process can be either equilibrated (weakening the rip) or transient for small wave forcing, resulting in rip current oscillations (Kennedy and Zhang, 2008).
} 


\subsection{Modeled instability event off Biscarrosse}

Figure 10 shows a snapshot of rip current flow advecting a passive tracer. The general pattern shows a rip flow biased towards the south and a strong cyclonic recirculation cell, very similar to that of Haas et al. (2003). It also suggests the presence of turbulence, i.e., meandering and offshore-developing instability with a mushroom-shaped pattern detaching from the rip recirculation cell. Figure 11 shows the instability development with a filament of negative vorticity meandering as it propagates offshore, much like the sinuous mode of Haller and Dalrymple (2001). Maximum vorticity within the rip current is larger than 0.05 $s^{-1}$, which is on the order of the vorticity scaling used in the previous section. A time- and length-scale estimation of this instability event is around $30 \mathrm{~min}$ and $200 \mathrm{~m}$ respectively, consistent with Eq. 8. It is an illustration of VLF modes produced in the model.

\subsection{Observation spectrum}

Bruneau et al. (2009a) noted VLF oscillations in Biscarrosse time-series with periods of 10-30 min. Low-pass filtering of the data (at S4 in the rip neck) indicates that these VLF oscillations are correlated with the presence of rip currents (Fig. 12). This is also true for the model but, while its skills are excellent at predicting the phase of slow variations associated with rip events (given tide and wave forcing), single VLF oscillations in the model are not coincidental with observed events.

For further comparison with the model, it may be useful to analyze the rip current frequency spectrum. However, the power spectrum in Figure 13 is broad and shows energy at all frequencies, increasing for slower oscillations; peak frequencies are blurred by abrupt transitions projecting over the whole spectrum. These are due to the location of S4 station on the edge of the rip channel, which sees fast flow reversal as the rip current shifts position during tidal ebb and flood cycles.

A Morlet wavelet analysis is presented in Figure 14 that shows the distribution of signal energy during the first three rip events. Again, the patterns tend to reflect sharp transitions during rip events projecting over a wide range of scales. Yet, physically meaningful oscillations are apparent at the tidal and half-tidal frequencies, as they affect breaking conditions 
1 around the rip channel (given by $\gamma_{b}>0.3$ and represented in red color in the time-series of 2 Fig. 14). More importantly here, energy peaks are present in the VLF range and are only 3 apparent during rip events (consistent with Fig. 12).

\section{5.4. Model spectrum}

In the model, the Fourier and wavelet transforms are in agreement with observations 6 although the amplitude is lower, especially in the VLF range (Fig. 12). Yet, the model 7 reproduces a large part of the observed VLF signal. Since VLF motions are intrinsic in the 9 by intrinsic rather than extrinsic processes.

Similarly to observations, peak VLF amplitudes in the model are correlated with rip current events (Fig. 14, left panels). There is an apparent model-data mismatch of the relative peak VLF amplitudes in different events (bottom panels of Fig. 14; e.g., larger amplitude is seen during the first observed event in the data, during the second in the model). Part of the discrepancy may be due to model error in reproducing mean rip events and thus mean-eddy conversion. Another part is stochastic since VLF motions arising from instability processes feed from rip currents but with unpredictable outcome. Specifically, there are less than 8 VLF oscillations during each rip event, which produces for a particular rip event more than $50 \%$ error on VLF variance (assuming normal distribution) ${ }^{7}$.

We note that in contrast to observations, the model produces a background of VLF energy that is apparent at high tides between rip events (see in particular the black part of time-series curve in Fig. 14). This phenomenon seems associated with long meandering jets emerging from the shore break at high tides (clearly visible on animations of surface currents). Because it is absent from the data, we conclude that this high-tide VLF signal is spurious and presumably results from insufficient model dissipation in the swash-zone. A parametrization of swash zone dynamics (Brocchini and Bellotti, 2002; Antuono et al., 2007) will be part of future model developments.

${ }^{7}$ From Cochran's theorem, the standard error of sample variance is $\sqrt{2 /(n-1)} \sigma^{2}$, where $n$ is the number of events and $\sigma^{2}$ the true variance. 
Next, to identify the possible role of wave-current interactions, we designed an experiment without current effect on waves (using the same wave model equations but omitting the velocity terms as in Weir et al., 2011). In this case, VLF motions are slightly more energetic but not significantly so. Therefore, wave-current interactions play no substantial part in our case and much of our VLF motions results from jet instabilities with properties agreeing with linear instability theories (Eq. 8).

\subsection{Resolution convergence and turbulent closure}

Part of the missing VLF energy in the model may be related to wave forcing variability not accounted for; another part may be due to still insufficient numerical resolution. Experiments with variable resolution $(5,10$, and $20 \mathrm{~m})$ shows that the numerical solution has not reached convergence at 5-m resolution since VLF energy keeps increasing from 20 to 10 and $5 \mathrm{~m}$ (especially the higher range of frequencies). Therefore, higher resolution simulations will be needed to assess the maximum energy that can be reached through instability processes.

The question of turbulent closure is of interest for resolution convergence. Here, we use a resolution and flow-dependent Smagorinsky model with coefficient $C_{S}=0.1$, which is on the order of estimates from Large Eddy Simulations ${ }^{8}$ (Meyers and Sagaut, 2006). Different values of $C_{S}$ tend to only affect the VLF part of the spectrum (the energy increases/decreases for smaller/larger values). Besides the Smagorinsky coefficient, the choice of closure model can also be questioned with respect to turbulent regimes. VLF eddies being much larger than local water depth, the turbulent regime would obey a 2D inverse energy cascade and forward enstrophy cascade. Leith model (Leith, 1968) would be more appropriate in this case. An inverse cascade would be consistent with an increase of energy towards lower frequencies in the VLF range.

In any case, bottom friction provides the most important sink for kinetic energy of the rip system. In particular, the VLF energy spectrum is sensitive to bottom roughness (not

\footnotetext{
${ }^{8}$ In addition to physical closure, numerical closure of the discretized equations is guaranteed by implicit numerical diffusion in ROMS upstream-biased advection scheme (Shchepetkin and Mcwilliams, 1998). This numerical diffusion is small at resolutions of order $10 \mathrm{~m}$ or less.
} 
4 5.6. Tridimensional effect dynamics.

shown). A decrease of roughness length from $1 \mathrm{~cm}$ to $0.1 \mathrm{~mm}$ increases VLF energy but at the expense of realistic persistent rip currents (Sec 4.2 and Fig. 9). The model parameters appear well constrained in this respect.

VLF oscillations are nearly absent from 2D simulations. In Figure 13, all frequencies are considerably weaker than in the 3D model and much weaker than in the data. Consistently, Bruneau et al. (2009a) failed to capture VLF frequencies in their standard 2D simulations and significant viscosity reduction was required to generate instabilities in their case. We interpret this result as evidence that the barotropic component of $2 \mathrm{D}$ equations may not produce enough current shear to trigger instability.

In linear models, lateral or bottom friction increases the jet spreading of the classical planar jet solution and causes the centerline velocity to decay more rapidly. We mentioned that the bottom slope acts in the same direction because depth-averaged flow continuity overwhelms the effect of vortex stretching (Haller and Dalrymple, 2001). Interestingly and as already predicted by Arthur (1962), this balance may be affected by tridimensionality. After rip currents leave the surf zone they tend to be confined to a layer of thickness equal to the depth at the seaward edge of the surf zone (Fig. 8). This has a double effect. On one hand, surface confinement reduces bottom interaction and associated stretching effect. On the other hand, bottom friction decreases in the process. More importantly, a surfaceintensified jet has more intense centerline velocity than its depth-averaged flow on a sloping beach (due to continuity). From our results, nonlinear interactions between baroclinic and barotropic components also appear to increase the barotropic flow. Overall, the increase of shear production from surface intensification appears to easily dominate over depth-averaged

\subsection{Analysis of steady-state simulation}

To analyze further the intrinsic part of model variability, we designed a statistically stationary experiment (or steady-state simulation) using the low-energy conditions of June 
12007 as persistent forcing. This is a rather strong rip event that has the advantage of being 2 relatively isolated from the surrounding circulation, contrarily to the chaotic fields produced 3 by high-energy conditions. The result shows a range of VLF oscillations at about 30 min 4 period in agreement with shear instability scaling (Sec. 5.1).

To localize in space the instability process, we compute the mean-eddy conversion terms in the stationary experiment (e.g., Marchesiello et al., 2003):

$$
K m K e=-\overline{u^{\prime} u^{\prime}} \frac{\partial \bar{u}}{\partial x}-\overline{u^{\prime} v^{\prime}} \frac{\partial \bar{u}}{\partial y}-\overline{u^{\prime} v^{\prime}} \frac{\partial \bar{v}}{\partial x}-\overline{v^{\prime} v^{\prime}} \frac{\partial \bar{v}}{\partial y}
$$

Here, $\bar{u}$ and $u^{\prime}$ indicate time-averaged and perturbation fields over the 8-hour-long simulation (assuming well-behaved eddy-mean decomposition) .

Figure 15 (left panel) shows KmKe together with contours of strain rate ${ }^{9}$ and velocity vectors. When conversion is positive, it indicates the work of shear instability. In contrast, negative values indicate feedback to the mean flow. The maximum energy conversion to eddies is clearly in the feeder zone, coincidental with a maximum strain rate (essentially a contraction process here). The instability decreases offshore along the jet axis as predicted for sinuous instability modes. However, a new strong maximum appears at the rip head. This area is characterized by surface-trapped currents in relatively deep water, where bottom friction is weaker than in the rip channel. The offshore growth rate of disturbances is thus less impaired by friction. It allows the offshore currents to wander about as a wavy (ribbonlike) sinuous mode (Fig. 11). On the other hand, KmKe is negative in the center and onshore flow area of the cyclonic recirculation cell, suggesting that the onshore flow and recirculation cell are reinforced by advective processes. Consistently, a simulation with increased viscosity (not shown) where no instability can develop produces a weaker recirculation cell. This result is similar to that of Haas et al. (2003) from bottom friction sensitivity experiments.

Figure 15 (right panel) presents the eddy kinetic energy (EKE) of this equilibrated solution. The structure of EKE contrasts with that of eddy production (KmKe; left panel). Both

\footnotetext{
${ }^{9}$ The strain rate $|S|=\sqrt{\left[\frac{\partial u}{\partial x}-\frac{\partial v}{\partial y}\right]^{2}+\left[\frac{\partial u}{\partial y}+\frac{\partial v}{\partial x}\right]^{2}}$ is the sum of stretching and shearing strain respectively.
} 
1 EKE and KmKe have maxima in the feeder zone but the largest patch of eddy variability is 2 located offshore at the rip head. Our understanding is that instabilities are mostly generated 3 in the feeder zone but their linear and nonlinear growth are along the jet axis (justifying 4 spatial stability analysis as in Haller and Dalrymple, 2001). The rip channel appears as a 5 stabilizing region, probably due to bottom friction and topographic channeling, but reduced

6 friction in deeper water allows instabilities to grow more freely and produce wavy filaments 7 akin to sinuous modes (Fig. 11).

\section{Conclusion}

We present some validation of tridimensional rip current modeling in the Aquitanian coastal zone using in-situ and remote video sensing. We show the benefits of 3D versus 2D modeling for the simulation of mean rip currents and their low-frequency variability. The 3D model appears also more robust than its 2D counterpart with respect to parameter sensitivity (bottom friction) as more physics is added to the problem. This idea is reminiscent of that of Weir et al. (2011) regarding the feedback of currents to wave forcing. They found that bottom friction in uncoupled circulation models can be tuned to mimic the behavior of wave-current coupled models, but the latter requires less ad hoc tuning. Here, we conclude that tridimensional nearshore models may provide a valuable and cost-effective alternative to more usual 2D approaches, which miss the vertical flow structure and its nonlinear interaction with the $2 \mathrm{D}$ flow.

Our study suggests that intrinsic dynamics of nearshore circulation could explain a large part of low-frequency variability and be a serious alternative to low-frequency wave-forcing in rip currents (or at least a complementary process). There are large implications for the ejection of surf-zone material, i.e. shelf-surf tracer exchanges (Hally-Rosendahl et al., 2014). Recirculation cells would promote retention while pulsation and filament formation would do the opposite and increase dispersion out of the surf-zone. Further study of the intrinsic dynamics of wave-induced nearshore currents is thus of great interest. Questions arise as to the form the surface-intensified offshore jets take in relation to the density stratification and Coriolis force and what is their interaction with other shelf currents. Other questions require 
1 a better assessment of instability modes and their nonlinear development; the turbulent

2 regime of nearshore currents; the resolution needed to capture the essential dynamics; and 3 the parametrization of their energy dissipation.

\section{Acknowledgments}

5 This research has received support from grants by ANR (COMODO: ANR-11-MONU6 005) and LEFE/INSU (COMODO-WAVES) in France; NSF (OCE-1344970) and ONR 7 (N000141410626) in the USA. It was also granted access to the HPC resources of GENCI8 IDRIS under allocation 2014-017298. We thank the EPOC/METHYS coastal dynamics 9 group for providing in-situ data from the June 2007 campaign and Philippe Bonneton for useful discussions. We also thank three anonymous reviewers for their careful reading of our manuscript and their insightful comments and suggestions. 
Almar, R., Castelle, B., Ruessink, B. G., Sénéchal, N., Bonneton, P., Marieu, V., 4 2010. Two- and threedimensional double-sandbar system behaviour under intense wave forcing and a meso-macro tidal range. Continental Shelf Research 30 (7), 781-792.

Almar, R., Castelle, B., Ruessink, G., Senechal, N., Bonneton, P., Marieu, V., 2009. High-frequency video observation of a double sandbar system under high-energy wave forcing. Journal of Coastal Research 56 , 1706-1710.

Antuono, M., Brocchini, M., Bellotti, G., 2007. Integral properties of the swash zone and averaging. part 3. longshore shoreline boundary conditions for wave-averaged nearshore circulation models. Journal of Fluid Mechanics 573, 399-415.

Arthur, R., 1962. A note on the dynamics of rip currents. Journal of Geophysical Research 67 (7), 2778-2779.

Bickley, W., 1939. The plane jet. Philosophical Magazine Series 7, 727-731.

Blaas, M., Dong, C., Marchesiello, P., McWilliams, J. C., Stolzenbach, K. D., 2007. Sediment-transport modeling on southern californian shelves: A ROMS case study. Continental Shelf Research 27 (6), 832 853.

Brocchini, M., Bellotti, G., 2002. Integral flow properties of the swash zone and averaging. part 2. shoreline boundary conditions for wave-averaged models. Journal of Fluid Mechanics 458, 269-281.

Bruneau, N., Bonneton, P., Castelle, B., Pedreros, R., 2011. Modeling rip current circulations and vorticity in a high-energy mesotidal-macrotidal environment. Journal of Geophysical Research: Oceans 116 (C7).

Bruneau, N., Castelle, B., Bonneton, P., Pedreros, R., 2009a. Very low frequency motions of a rip current system: observations and modeling. Journal of Coastal Research 56 (2), 1731-1735.

Bruneau, N., Castelle, B., Bonneton, P., Pedreros, R., Almar, R., Bonneton, N., Bretel, P., Parisot, J.-P., Sénéchal, N., 2009b. Field observations of an evolving rip current on a meso-macrotidal well-developed inner bar and rip morphology. Continental Shelf Research 29 (14), 1650 - 1662.

Butel, R., Dupuis, H., Bonneton, P., 2002. Spatial variability of wave conditions at french atlantic coast using in-situ data. Journal of Coastal Research 36, 96-108.

Castelle, B., Bonneton, P., Dupuis, H., Senechal, N., 2007. Double bar beach dynamics on the high-energy meso-macrotidal french aquitanian coast : A review. Marine Geology 245 (141-159).

Church, J. C., Thornton, E. B., 1993. Effects of breaking wave induced turbulence within a longshore current model. Coastal Engineering 20 (1-2), $1-28$.

De Vriend, H. J., Stive, M. J. F., 1987. Quasi-3d modelling of nearshore currents. Coastal Engineering $11(5-6), 565-601$.

Debreu, L., Marchesiello, P., Penven, P., Cambon, G., 2012. Two-way nesting in split-explicit ocean models: Algorithms, implementation and validation. Ocean Modelling 49-50 (0), $1-21$.

Haas, K. A., Svendsen, I. A., 2002. Laboratory measurements of the vertical structure of rip currents. Journal 
of Geophysical Research: Oceans 107 (C5), 15-1-15-19.

Haas, K. A., Svendsen, I. A., Haller, M. C., Zhao, Q., 2003. Quasi-three-dimensional modeling of rip current systems. Journal of Geophysical Research: Oceans 108 (C7), 3217.

Haller, M. C., Catalán, P. A., 2009. Remote sensing of wave roller lengths in the laboratory. Journal of Geophysical Research: Oceans 114 (C7).

Haller, M. C., Dalrymple, R. A., 2001. Rip current instabilities. Journal of Fluid Mechanics 433, $161-192$.

Hally-Rosendahl, K., Feddersen, F., Guza, R. T., 2014. Cross-shore tracer exchange between the surfzone and inner-shelf. Journal of Geophysical Research: Oceans 119 (7), 4367-4388.

Holland, K. T., Holman, R. A., Lippmann, T. C., Stanley, J., Plant, N., 1997. Practical use of video imagery in nearshore oceanographic field studies. IEEE J. Oceanic Engineering 22 (1), 81-92.

Holman, R., Haller, M. C., 2013. Remote sensing of the nearshore. Annual Review of Marine Science 5 (1), $95-113$.

Kennedy, A. B., 12 2003. A circulation description of a rip current neck. Journal of Fluid Mechanics 497, $225-234$.

Kennedy, A. B., Zhang, Y., 2008. The stability of wave-driven rip current circulation. Journal of Geophysical Research: Oceans 113 (C3).

Leith, C. E., 1968. Diffusion approximation for twodimensional turbulence. Physics of Fluids (1958-1988) $11(3), 671-672$.

Lippmann, T. C., Holman, R. A., 1989. Quantification of sand bar morphology: A video technique based on wave dissipation. Journal of Geophysical Research: Oceans 94 (C1), 995-1011.

Long, J. W., Özkan-Haller, H. T., 2009. Low-frequency characteristics of wave group-forced vortices. Journal of Geophysical Research-Oceans 114 (C08004).

MacMahan, J. H., Reniers, A. J. H. M., Thornton, E. B., Stanton, T. P., 2004. Surf zone eddies coupled with rip current morphology. Journal of Geophysical Research: Oceans 109 (C7).

MacMahan, J. H., Thornton, E. B., Reniers, A. J., 2006. Rip current review. Coastal Engineering 53 (2-3), 191 - 208, coastal Hydrodynamics and Morphodynamics Symposium celebrating the academic closing address of Jurjen A. Battjes.

Marchesiello, P., McWilliams, J. C., Shchepetkin, A., 2001. Open boundary conditions for long-term integration of regional oceanic models. Ocean Modelling 3 (1-2), 1 - 20.

Marchesiello, P., McWilliams, J. C., Shchepetkin, A., 2003. Equilibrium structure and dynamics of the california current system. Journal of Physical Oceanography 33, $753-783$.

McWilliams, J. C., Restrepo, J. M., Lane, E. M., 7 2004. An asymptotic theory for the interaction of waves and currents in coastal waters. Journal of Fluid Mechanics 511, 135-178.

Meyers, J., Sagaut, P., 2006. On the model coefficients for the standard and the variational multi-scale 
smagorinsky model. Journal of Fluid Mechanics 569, 287-319.

Özkan-Haller, H. T., Li, Y., 2003. Effects of wave-current interaction on shear instabilities of longshore currents. Journal of Geophysical Research: Oceans 108 (C5).

Penven, P., Debreu, L., Marchesiello, P., Mcwilliams, J., 2006. Evaluation and application of the roms 1-way embedding procedure to the central california upwelling system. Ocean Modelling 12 (1-2), 157-187.

Peregrine, D. H., 1998. Surf zone currents. Theor. Comput. Fluid Dyn. 10, 295-309.

Shchepetkin, A. F., Mcwilliams, J. C., 1998. Quasi-monotone advection schemes based on explicit locally adaptive dissipation. Monthly Weather Review 126, 1541-1580.

Shchepetkin, A. F., McWilliams, J. C., 2005. The regional oceanic modeling system (roms): a split-explicit, free-surface, topography-following-coordinate oceanic model. Ocean Modelling 9 (4), 347 - 404.

Shepard, F. P., Emery, K. O., Fond, E. C. L., 1941. Rip currents: A process of geological importance. The Journal of Geology 49 (4), 337-369.

Smagorinsky, J., 1963. General circulation experiments with the primitive equations. Monthly Weather Review 91 (3), 99-164.

Soulsby, R., 1995. Bed shear stresses due to combined waves and currents. In: Stive, M., Fredsøe, J., Hamm, L., Soulsby, R., Teisson, C., Winterwerp, J. (Eds.), Advances in Coastal Morphodynamics. Delft Hydraulics, Delft, The Netherlands, pp. 420-423.

Spydell, M., Feddersen, F., 2009. Lagrangian drifter dispersion in the surf zone: Directionally spread, normally incident waves. Journal of Physical Oceanography 39 (4), 809-830.

Uchiyama, Y., McWilliams, J., Shchepetkin, A., 2010. Wave-current interaction in an oceanic circulation model with a vortex-force formalism: Application to the surf zone. Ocean Modelling.

Uchiyama, Y., McWilliams, J. C., Restrepo, J. M., 2009. Wave-current interaction in nearshore shear instability analyzed with a vortex force formalism. Journal of Geophysical Research: Oceans 114 (C6), $\mathrm{n} / \mathrm{a}-\mathrm{n} / \mathrm{a}$.

Warner, J. C., Defne, Z., Haas, K., Arango, H. G., 2013. A wetting and drying scheme for ROMS. Computers and Geosciences $58(0), 54-61$.

Weir, B., Uchiyama, Y., Lane, E. M., Restrepo, J. M., McWilliams, J. C., 2011. A vortex force analysis of the interaction of rip currents and surface gravity waves. Journal of Geophysical Research: Oceans 116 (C5).

Wright, L., Short, A., 1984. Morphodynamic variability of surf zones and beaches: a synthesis. Marine Geology 56 (93-118).

Yu, J., Slinn, D. N., 2003. Effects of wave-current interaction on rip currents. Journal of Geophysical Research: Oceans 108 (C3). 


\section{List of Figures}

1 Coastal video monitoring: description of applications; (a) 5-camera system for Biscarrosse (France); (b) Spatial-temporal post-processed image showing wave dynamics. The image is generated from the high frequency acquisition of a cross-shore array of pixels. . . . . . . . . . . . . .

2 Model domain and interpolated bathymetry. The orange dot shows the measurement station S4 at the rip neck where model-data comparisons are presented. The cross-shore and alongshore distances are relative to the video camera position on the beach. The 0 isobath indicates the lowest astronomical tide. . . . . . . . . . . . . . . . . . . .

3 Normalized wave-breaking dissipation from 10-min averaged video data (top panels) and ROMS (bottom panels) after calibration (color range is from 0 to 1 ). Two examples are given: one for low-energy conditions (June 14 at 8:45 LT; left panels) and the other for high energy conditions (June 16 at 12.00 LT). On the first example, classical features of dissipation appear: high dissipation rates over the intertidal sand bar and near the shoreline with minimum dissipation in the trough and rip channels. At high-energy conditions, breaking occurs further offshore with less alongshore variability; some breaking also occurs over the subtidal bar around $600 \mathrm{~m}$ from shore (yellow patches in the upper left corner). . . . . . . . . . . . . . . . 31

4 Model-data comparison at station S4 for significant wave height (top) and cross-shore currents (bottom) for the period of June 2007 campaign (the sign convention is positive for shoreward currents.). A low-pass filter with a cutoff period of 30 minutes is applied to the observed and modeled currents. . . . .

5 Depth-averaged component of cross-shore velocity in ROMS2D and ROMS3D compared with total velocity from observational data (see Fig. 4 for total velocity from the model). . . . . . . . . . . . . . . . . . . 
6 Baroclinic Reynolds stress $\overline{u^{\prime} u^{\prime}}$ in $\mathrm{m}^{2} / \mathrm{s}^{2}$ (top) and its divergence, i.e. baroclinic advection, in $\mathrm{m} / \mathrm{s}^{2}$ (bottom) during the low-energy period. Depth-mean velocity vectors are overlaid. . . . . . . . . . . . . . .

7 Depth-averaged cross-shore momentum budget for the low-energy period of the entire rip system (top; averaged over a 300-m longshore distance around the rip channel) and along the rip current (bottom). Note that positive values of budget terms indicate a tendency to accelerate shoreward currents and decelerate seaward (rip) currents. The advection term is split between its barotropic (BT) and baroclinic (BC) parts. BC advection is shown by a thick black line. . . . . . . . . . . . . . . . . . . .

8 Snapshot (June 14 at 9 a.m.) of cross-shore currents along the rip channel (left) and sand bar (right); section locations are drawn in the inset. Note the strong shear generated seaward along the rip current, with current reversal near the bottom as in the laboratory measurements of Haas and Svendsen (2002). The right panel shows the profile of breaking-wave-driven onshore flow. 35

9 Model sensitivity to bottom roughness length $z_{0}$ at station S4. The model resolution is $10 \mathrm{~m}$ here and $z_{0}$ varies from $1 \mathrm{~cm}$ (standard case) to $1 \mathrm{~mm}$ and $0.1 \mathrm{~mm}$. The standard case is the same as in Fig. 4 and is the closest to

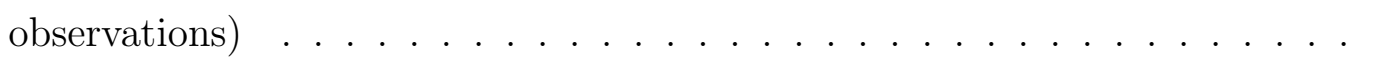

10 Snapshot (June 14 around 10 a.m.) of surface flow (vectors) carrying a passive tracer initially released in 1-m depth. Station S4 is marked by a blue spot at the neck of a rip current. A mushroom-shaped pattern at the rip head. Plot axes are cross-shore and longshore distances. . . . . . . . . . . . . . . 36

11 Sequence of ROMS surface vorticity showing the meandering of rip current from a steady-state simulation (low-energy conditions of June 2007). The sequence reads from left to right and top to bottom. The time interval between frames is $6 \mathrm{~min}$. The color scale of vorticity ranges from $\pm 0.04 \mathrm{~s}^{-1}$. . . . . 
12 Low and high-pass filtered cross-shore (wave-averaged) velocity time series from observed data at station S4 (June 13-17 2007). Rip currents are represented by low-pass events (grey curve) and VLF oscillations by the high-pass signal (black curve). The filter's cutoff period is 1 hour. . . . . . . . . . . . . 37

13 Frequency spectra of rip neck currents (cross-shore velocity at station S4). The model is compared with in situ data from the 5-day Biscarrosse campaign of 2007. The top panel features the 3D and 2D model solutions at $5 \mathrm{~m}$ resolution; the bottom panel shows the 3D model at 5, 10, and $20 \mathrm{~m}$ resolutions. 38

14 Morlet wavelet analysis of rip neck (cross-shore velocity at station S4). The model is compared with in situ data from the first 2 days of the 2007 Biscarrosse campaign, showing 3 rip events. The time series are presented on top with red color during breaking conditions in the rip channel $\left(\gamma_{b}>0.3\right)$. The contours (bottom panels) represent a percentage of the total signal's energy in the time and frequency domain: model and observations are only compared qualitatively here. The middle panel shows the entire energy spectrum while the lower panel focuses on the VLF range (in this case, the time-series are first high-pass filtered -1 hour - to better extract the VLF peaks; see text).

15 Mean-eddy conversion KmKe (left) and eddy kinetic energy EKE (right) in the rip current system from an 8-hour steady-state simulation of June 2007 low-energy conditions. Strain contours are overlaid in the KmKe figure; velocity vectors in both. . . . . . . . . . . . . . . . . . 40 

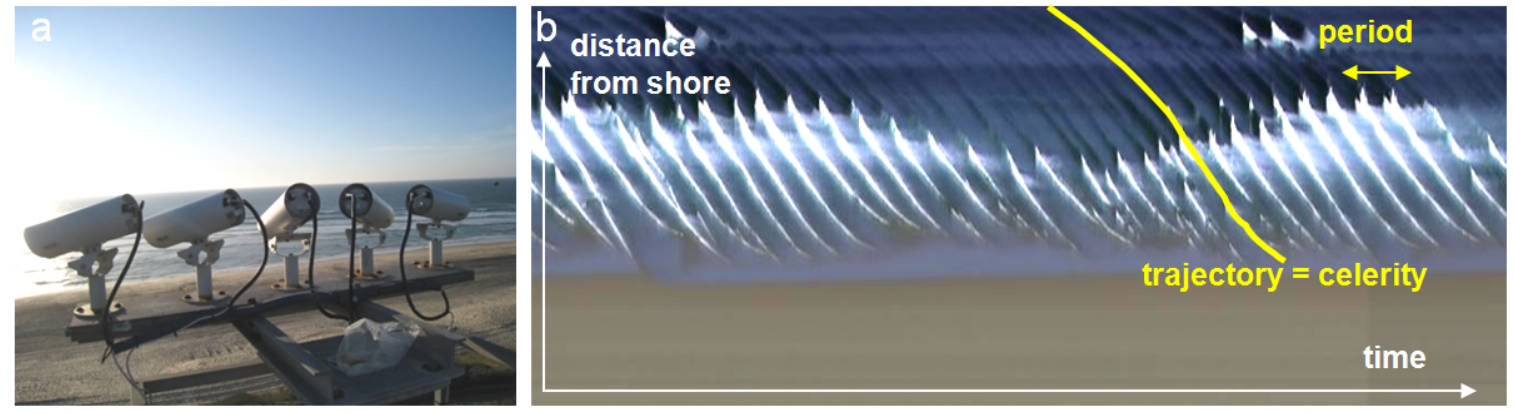

Figure 1: Coastal video monitoring: description of applications; (a) 5-camera system for Biscarrosse (France); (b) Spatial-temporal post-processed image showing wave dynamics. The image is generated from the high frequency acquisition of a cross-shore array of pixels. 


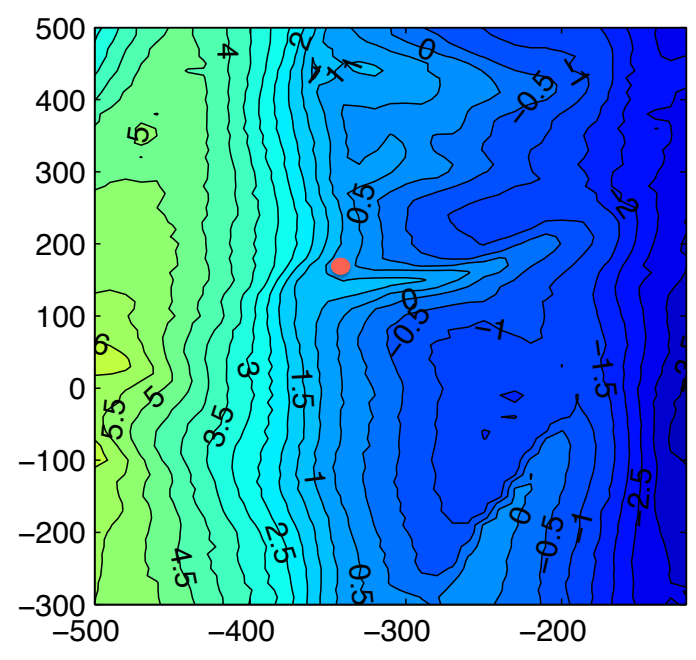

Figure 2: Model domain and interpolated bathymetry. The orange dot shows the measurement station S4 at the rip neck where model-data comparisons are presented. The cross-shore and alongshore distances are relative to the video camera position on the beach. The 0 isobath indicates the lowest astronomical tide. 
Low-energy conditions

High-energy conditions
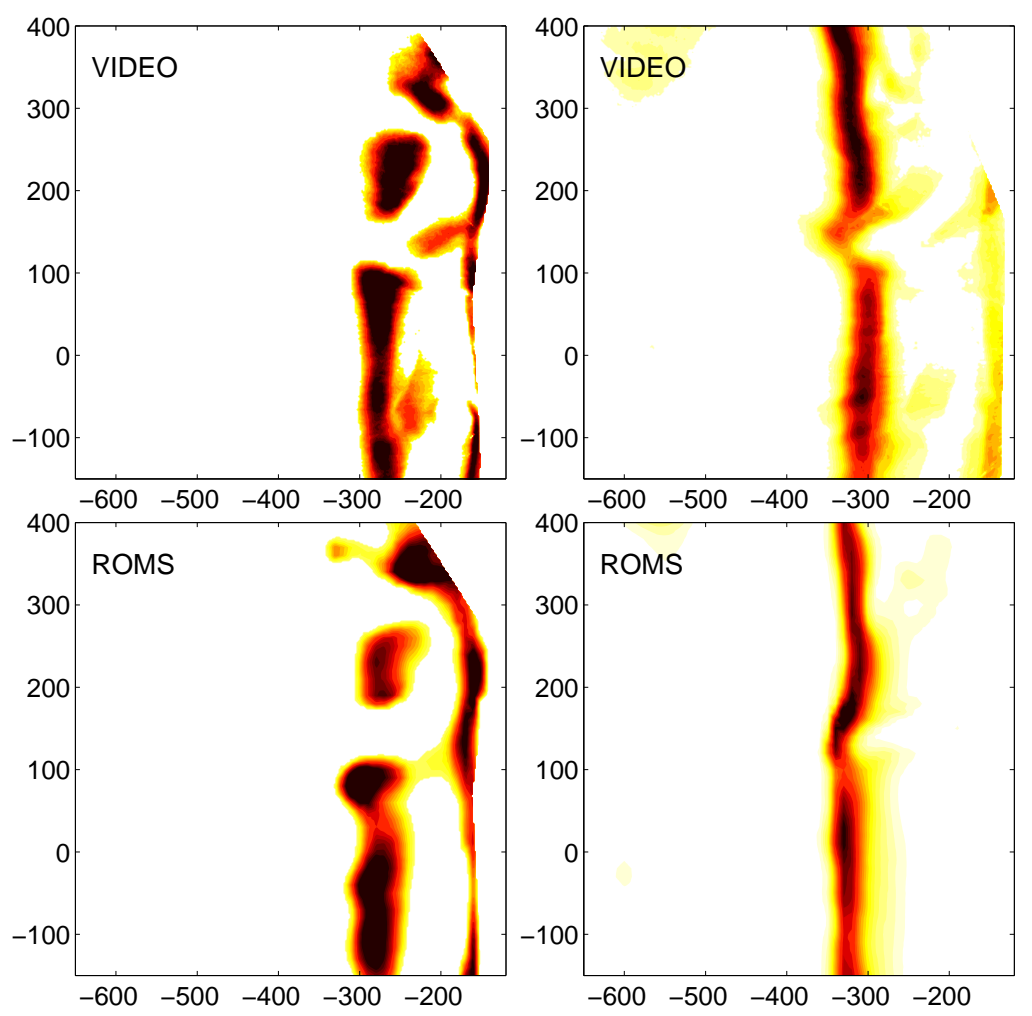

Figure 3: Normalized wave-breaking dissipation from 10-min averaged video data (top panels) and ROMS (bottom panels) after calibration (color range is from 0 to 1 ). Two examples are given: one for low-energy conditions (June 14 at 8:45 LT; left panels) and the other for high energy conditions (June 16 at 12.00 LT). On the first example, classical features of dissipation appear: high dissipation rates over the intertidal sand bar and near the shoreline with minimum dissipation in the trough and rip channels. At high-energy conditions, breaking occurs further offshore with less alongshore variability; some breaking also occurs over the subtidal bar around $600 \mathrm{~m}$ from shore (yellow patches in the upper left corner). 


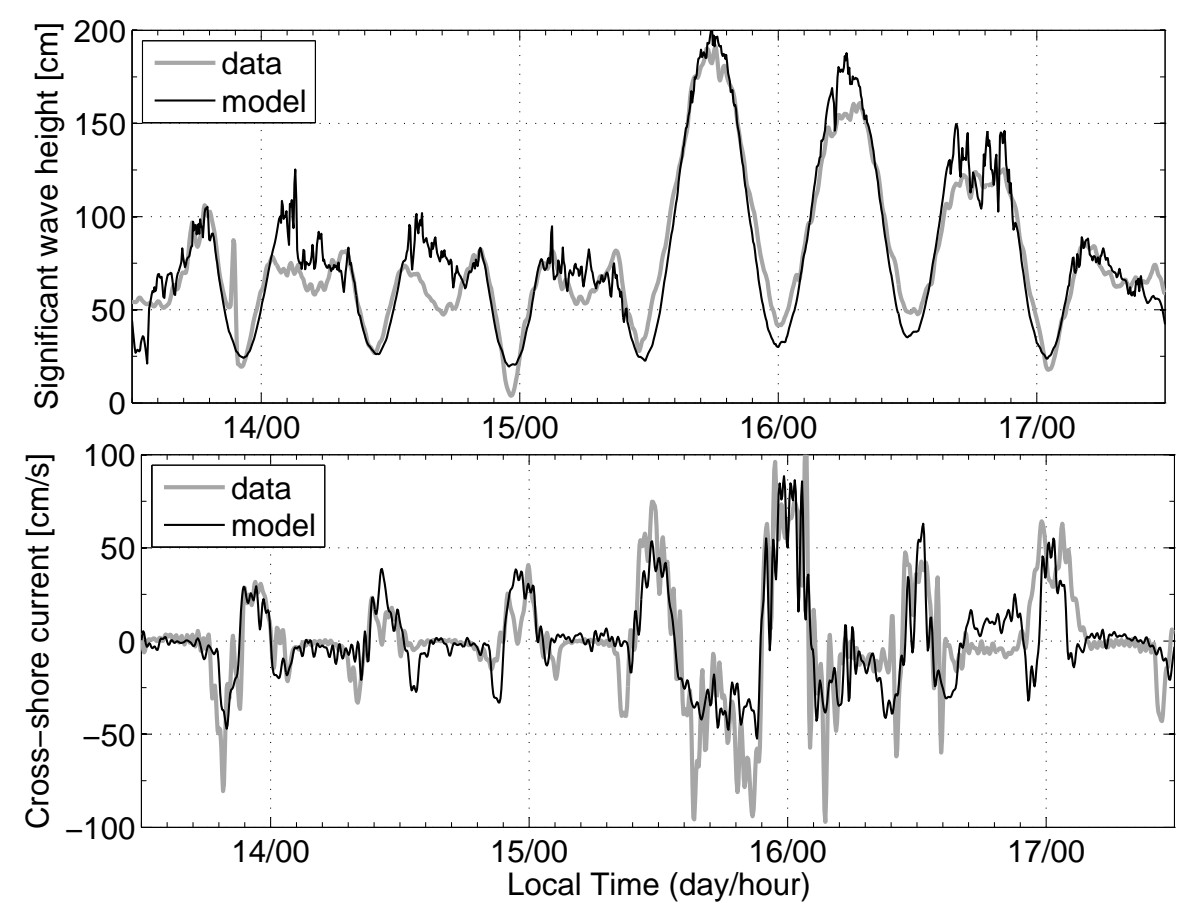

Figure 4: Model-data comparison at station S4 for significant wave height (top) and cross-shore currents (bottom) for the period of June 2007 campaign (the sign convention is positive for shoreward currents.). A low-pass filter with a cutoff period of 30 minutes is applied to the observed and modeled currents.

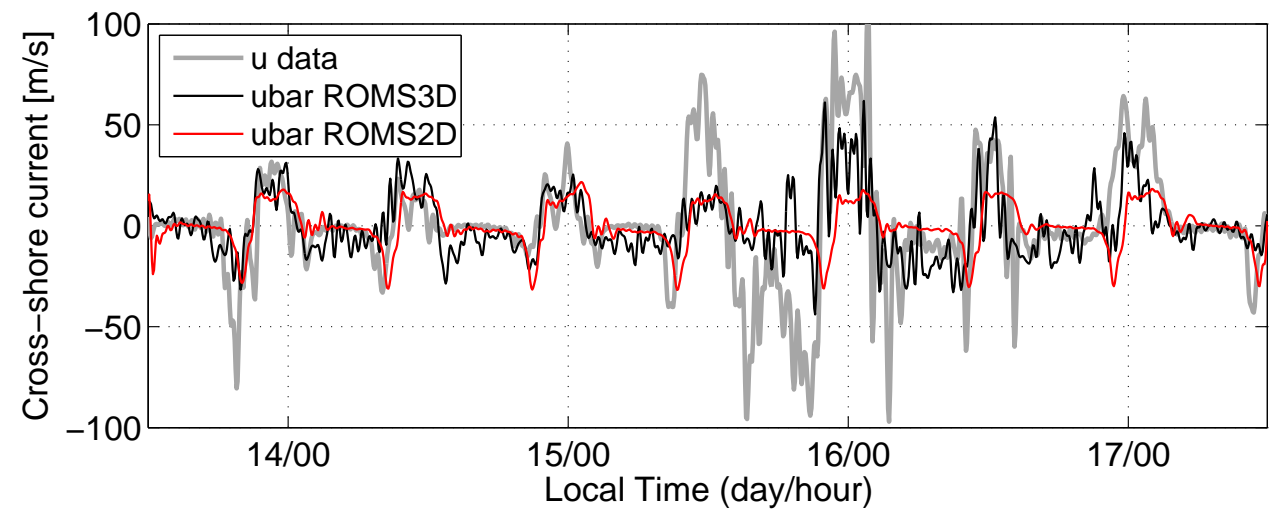

Figure 5: Depth-averaged component of cross-shore velocity in ROMS2D and ROMS3D compared with total velocity from observational data (see Fig. 4 for total velocity from the model). 

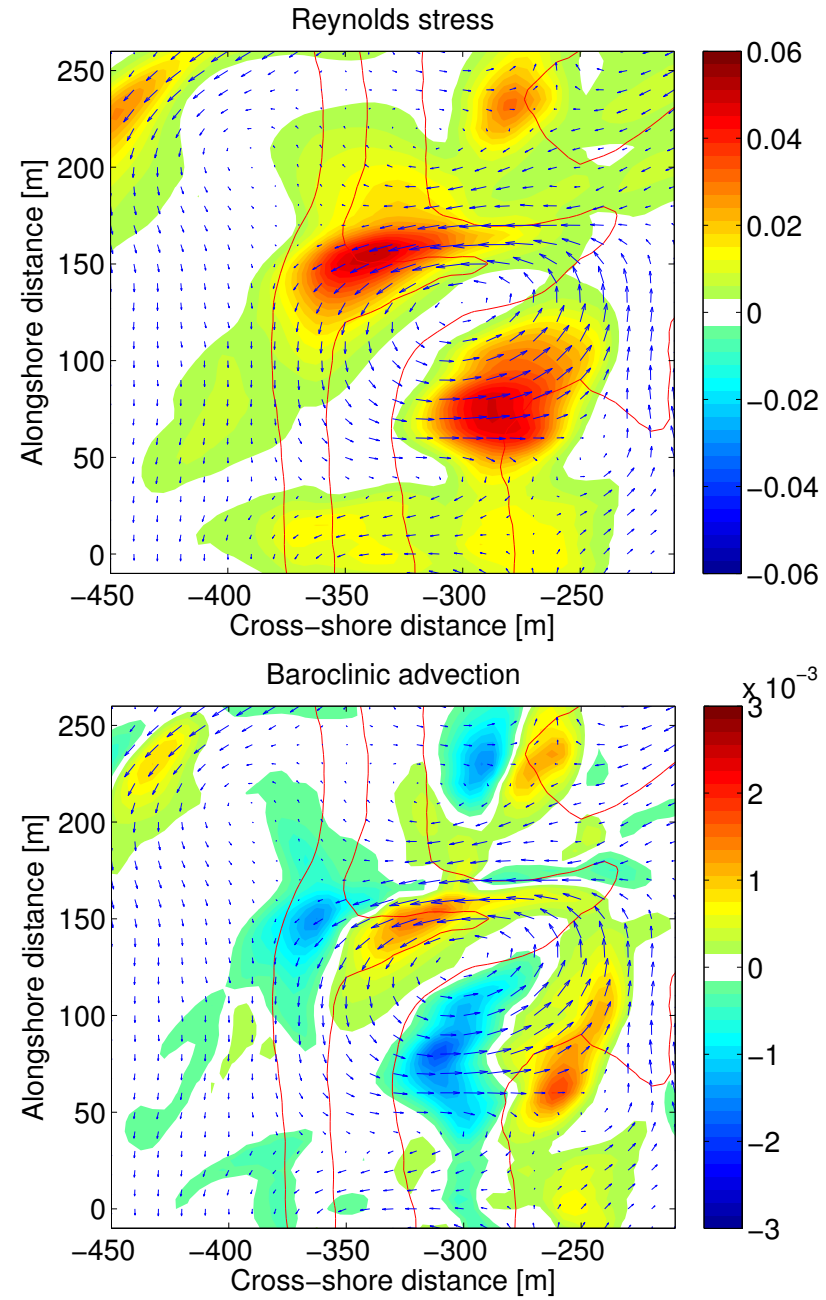

Figure 6: Baroclinic Reynolds stress $\overline{u^{\prime} u^{\prime}}$ in $\mathrm{m}^{2} / \mathrm{s}^{2}$ (top) and its divergence, i.e. baroclinic advection, in $\mathrm{m} / \mathrm{s}^{2}$ (bottom) during the low-energy period. Depth-mean velocity vectors are overlaid. 

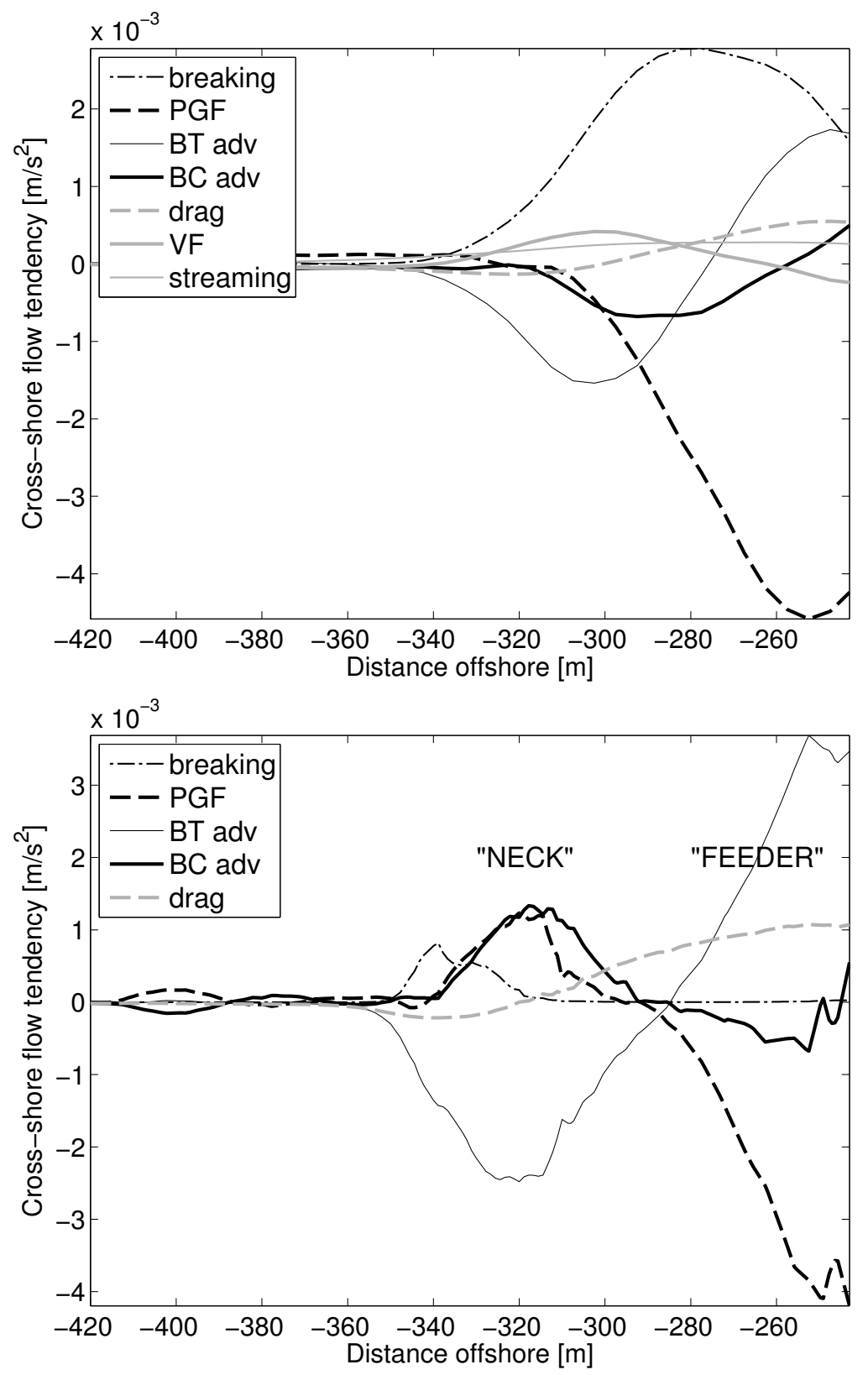

Figure 7: Depth-averaged cross-shore momentum budget for the low-energy period of the entire rip system (top; averaged over a 300-m longshore distance around the rip channel) and along the rip current (bottom). Note that positive values of budget terms indicate a tendency to accelerate shoreward currents and decelerate seaward (rip) currents. The advection term is split between its barotropic (BT) and baroclinic (BC) parts. $\mathrm{BC}$ advection is shown by a thick black line. 

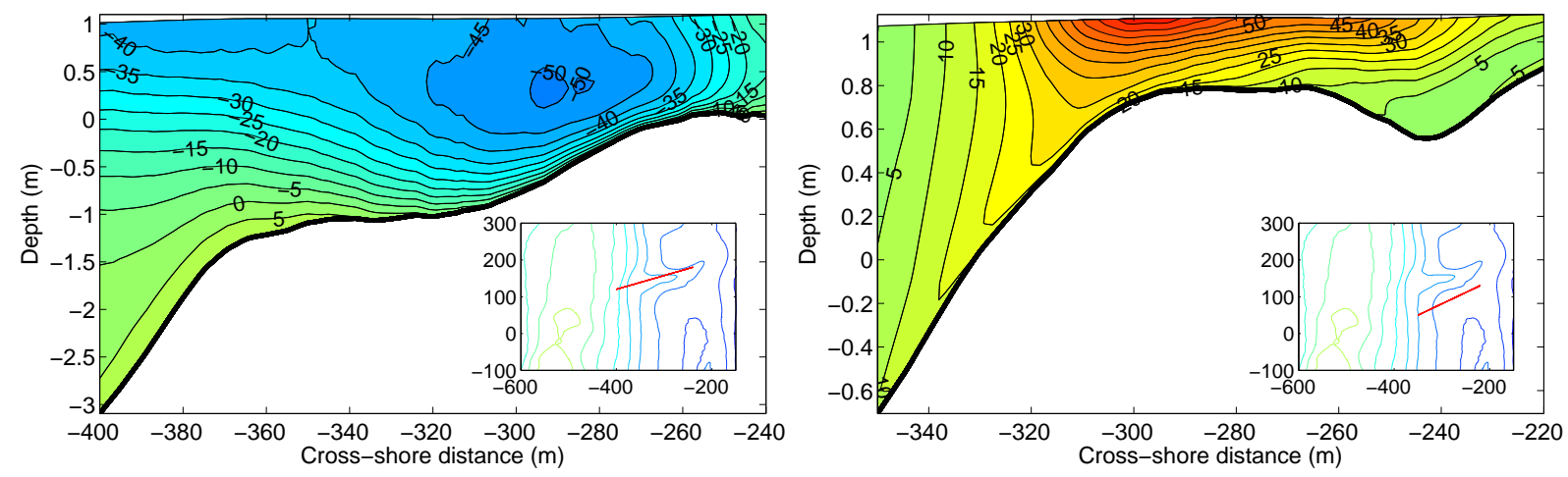

Figure 8: Snapshot (June 14 at 9 a.m.) of cross-shore currents along the rip channel (left) and sand bar (right); section locations are drawn in the inset. Note the strong shear generated seaward along the rip current, with current reversal near the bottom as in the laboratory measurements of Haas and Svendsen (2002). The right panel shows the profile of breaking-wave-driven onshore flow.

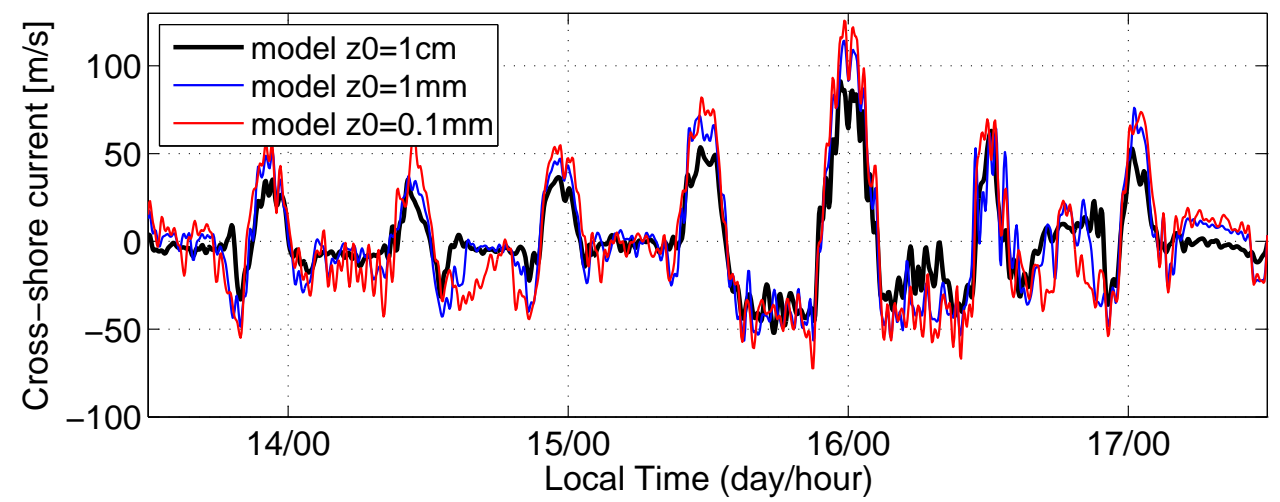

Figure 9: Model sensitivity to bottom roughness length $z_{0}$ at station S4. The model resolution is $10 \mathrm{~m}$ here and $z_{0}$ varies from $1 \mathrm{~cm}$ (standard case) to $1 \mathrm{~mm}$ and $0.1 \mathrm{~mm}$. The standard case is the same as in Fig. 4 and is the closest to observations) 


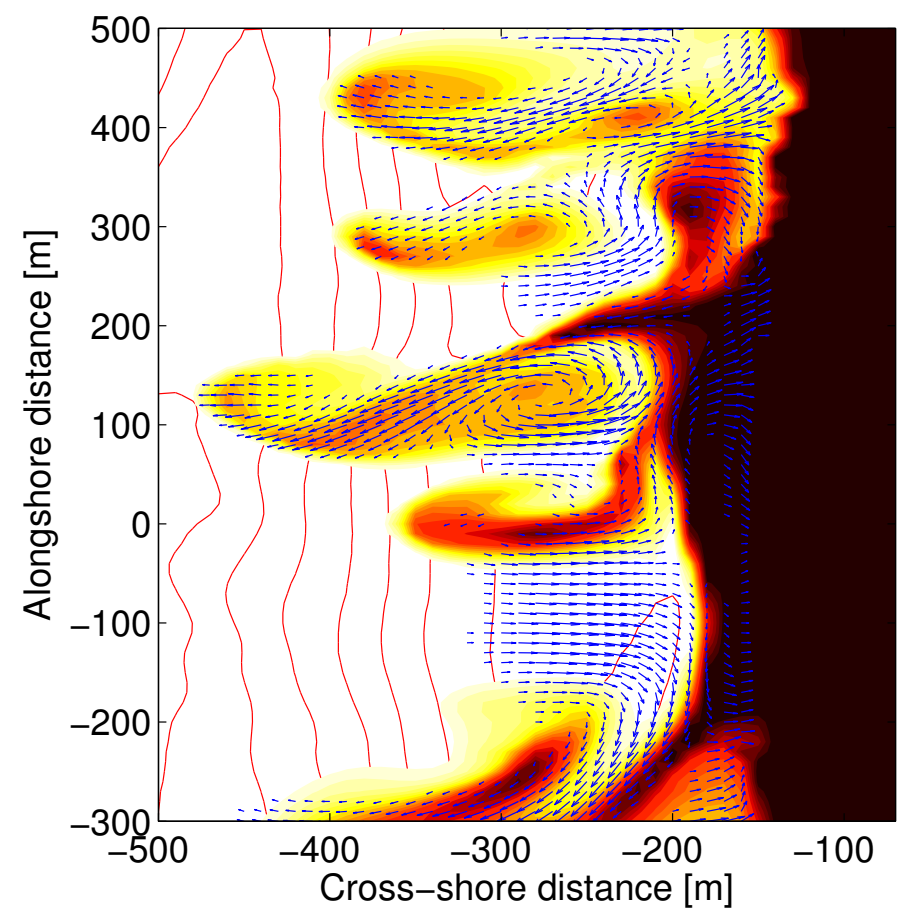

Figure 10: Snapshot (June 14 around 10 a.m.) of surface flow (vectors) carrying a passive tracer initially released in 1-m depth. Station S4 is marked by a blue spot at the neck of a rip current. A mushroom-shaped pattern at the rip head. Plot axes are cross-shore and longshore distances. 

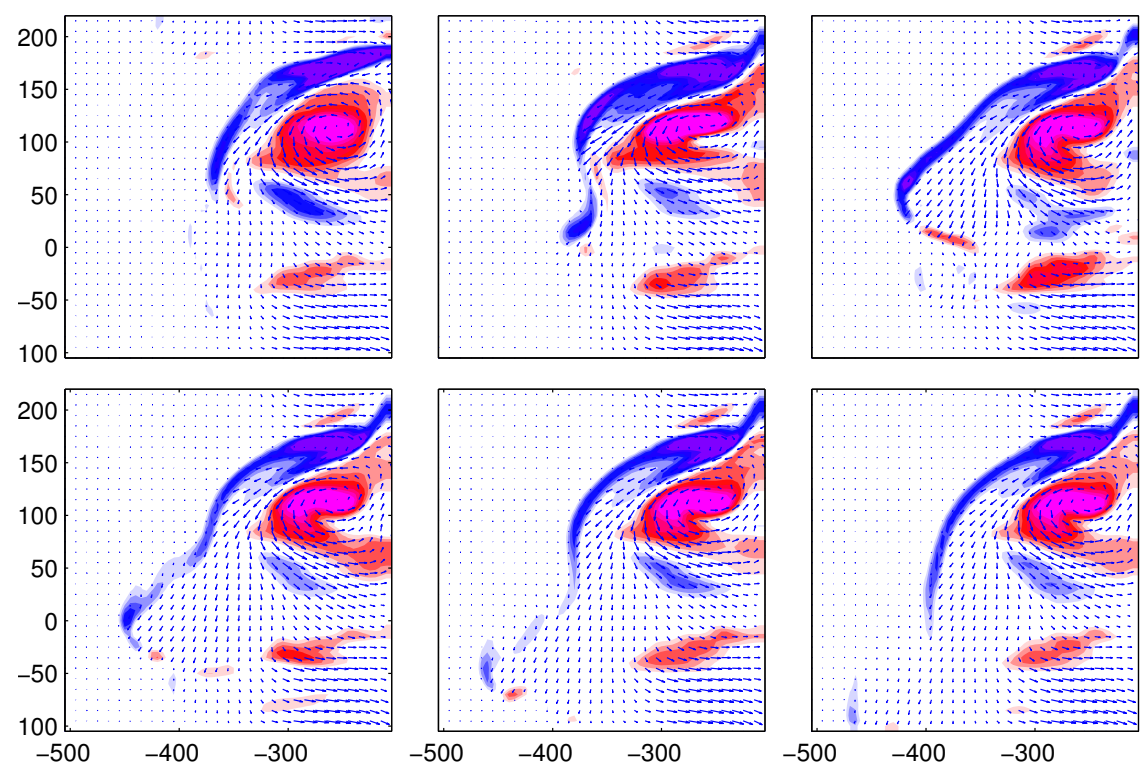

Figure 11: Sequence of ROMS surface vorticity showing the meandering of rip current from a steady-state simulation (low-energy conditions of June 2007). The sequence reads from left to right and top to bottom. The time interval between frames is $6 \mathrm{~min}$. The color scale of vorticity ranges from $\pm 0.04 \mathrm{~s}^{-1}$.

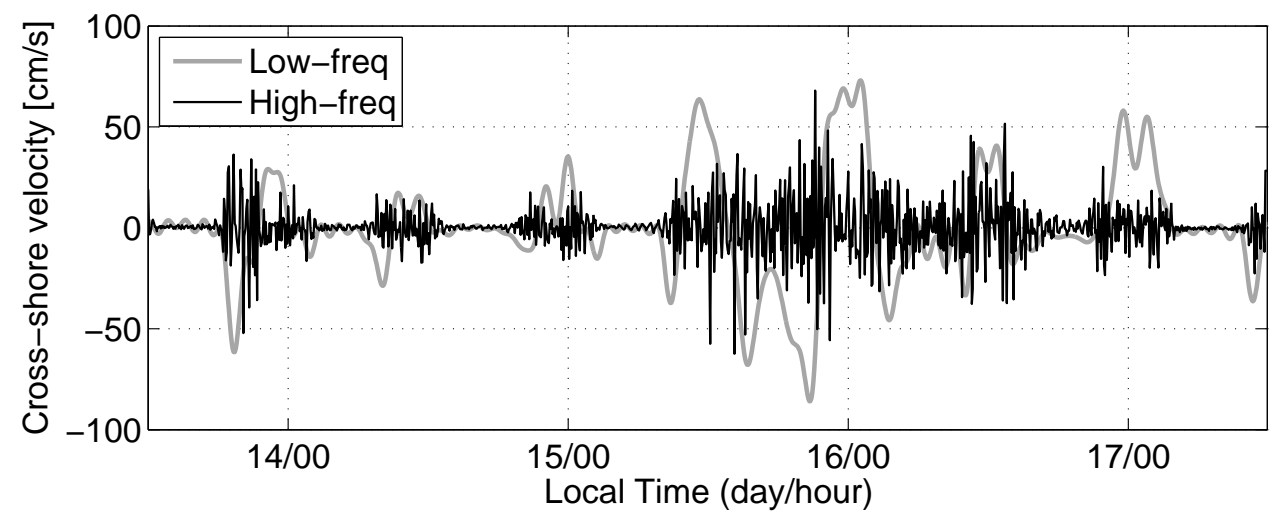

Figure 12: Low and high-pass filtered cross-shore (wave-averaged) velocity time series from observed data at station S4 (June 13-17 2007). Rip currents are represented by low-pass events (grey curve) and VLF oscillations by the high-pass signal (black curve). The filter's cutoff period is 1 hour. 

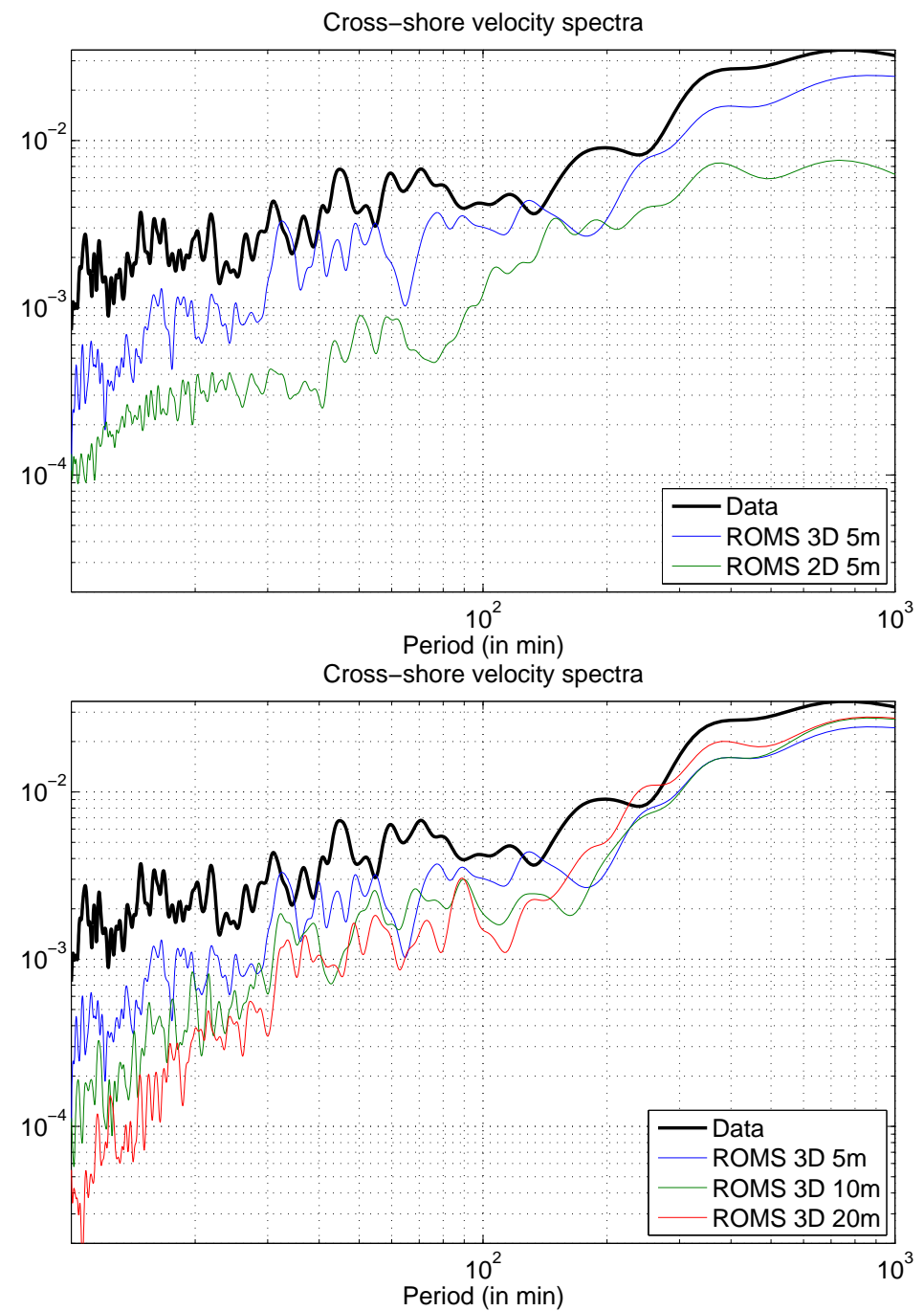

Figure 13: Frequency spectra of rip neck currents (cross-shore velocity at station S4). The model is compared with in situ data from the 5-day Biscarrosse campaign of 2007. The top panel features the 3D and 2D model solutions at $5 \mathrm{~m}$ resolution; the bottom panel shows the $3 \mathrm{D}$ model at 5,10 , and $20 \mathrm{~m}$ resolutions. 

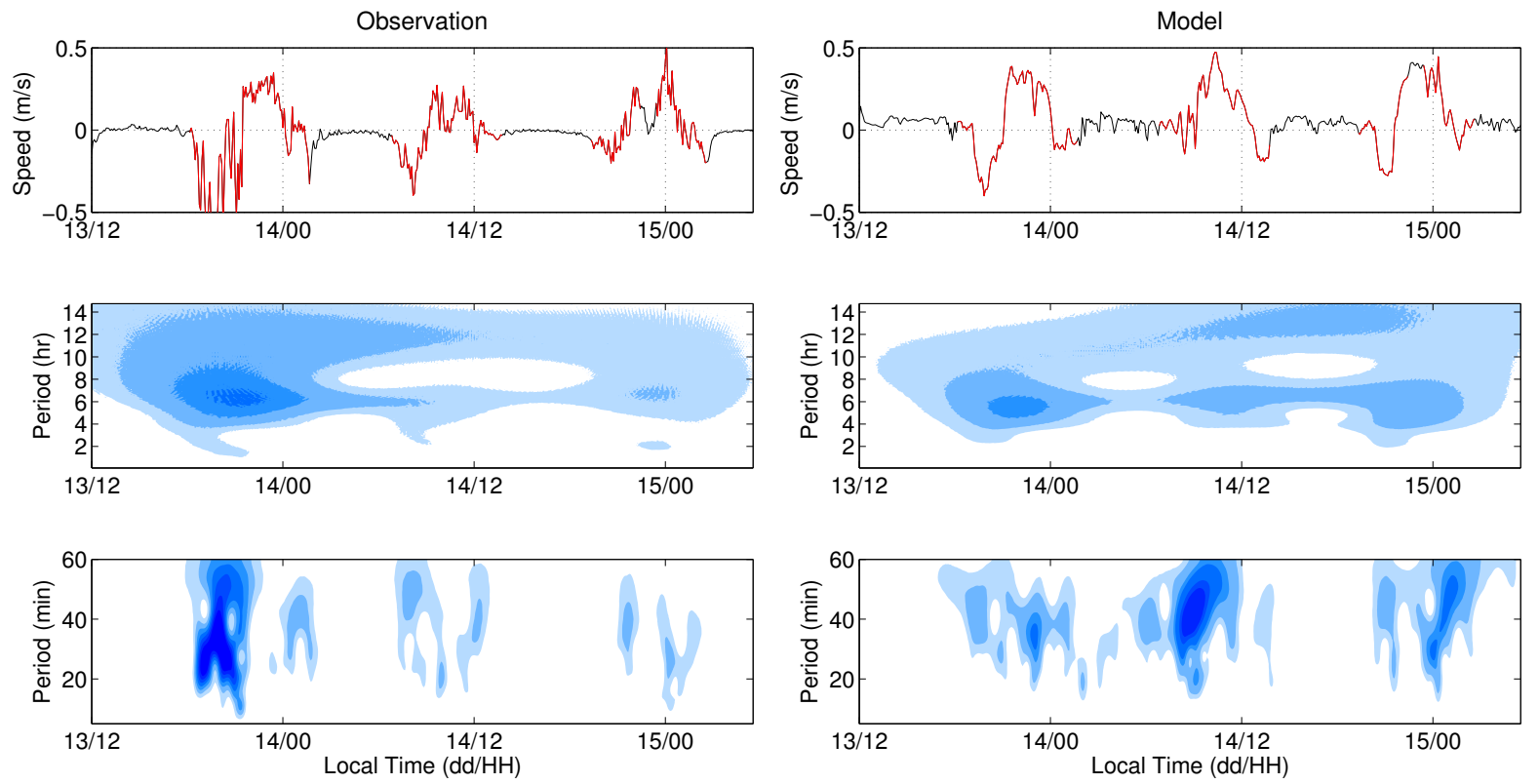

Figure 14: Morlet wavelet analysis of rip neck (cross-shore velocity at station S4). The model is compared with in situ data from the first 2 days of the 2007 Biscarrosse campaign, showing 3 rip events. The time series are presented on top with red color during breaking conditions in the rip channel $\left(\gamma_{b}>0.3\right)$. The contours (bottom panels) represent a percentage of the total signal's energy in the time and frequency domain: model and observations are only compared qualitatively here. The middle panel shows the entire energy spectrum while the lower panel focuses on the VLF range (in this case, the time-series are first high-pass filtered - 1 hour - to better extract the VLF peaks; see text). 

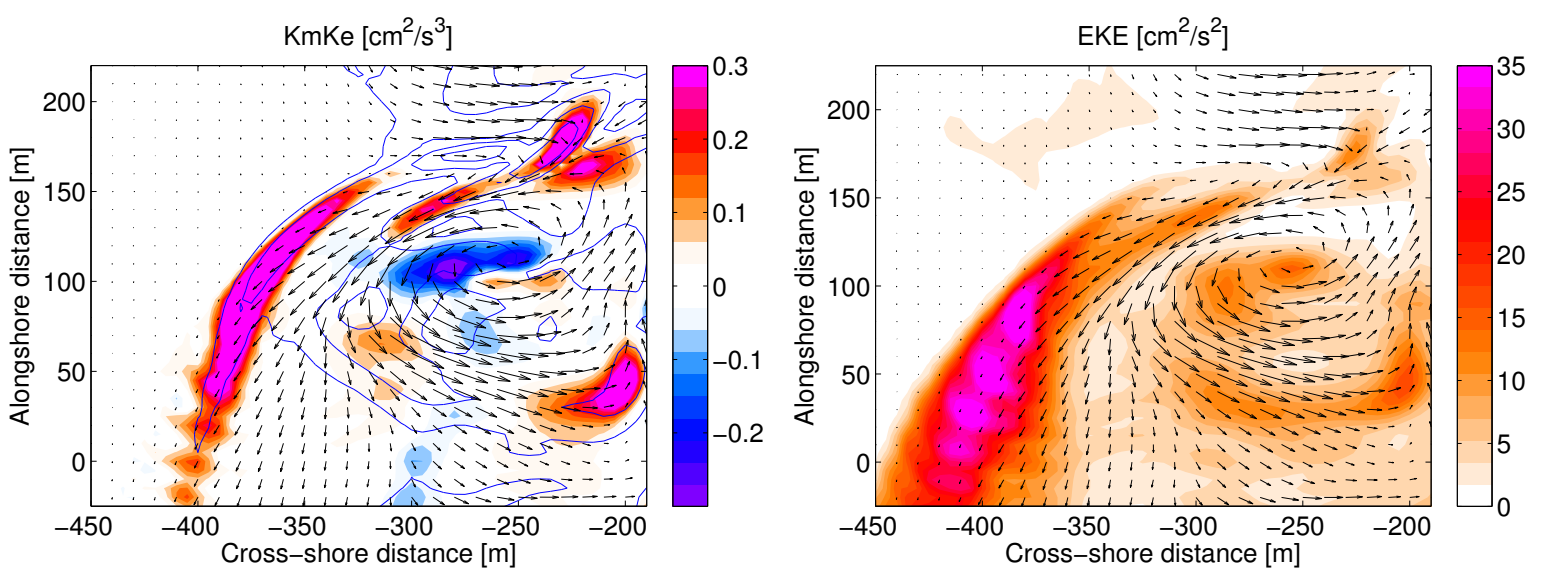

Figure 15: Mean-eddy conversion KmKe (left) and eddy kinetic energy EKE (right) in the rip current system from an 8-hour steady-state simulation of June 2007 low-energy conditions. Strain contours are overlaid in the KmKe figure; velocity vectors in both. 